\title{
Esiti di cifoplastica: infezione, rifrattura o necrosi asettica?
}

F.Giudici, A.Zagra

IRCCS Istituto Ortopedico Galeazzi, Milano

ABSTRACT Kyphoplasty complication: infection, re-fracture or aseptic
necrosis?
The present case report describes our experience of a rare complication of
kyphoplasty in an osteoporotic vertebral fracture.

\section{Introduzione}

La vertebroplastica e la cifoplastica hanno avuto nell'ultimo decennio un ruolo importante nel trattamento dei cedimenti vertebrali. Essendo considerati interventi relativamente semplici, si è avuto un progressivo incremento del numero degli interventi eseguiti. In realtà le complicazioni possibili sono diverse: rifratture, infezioni, "fughe" del cemento, osteonecrosi. Il caso clinico presentato racchiude alcune possibili complicazioni che si possono avere con queste tecniche chirurgiche.

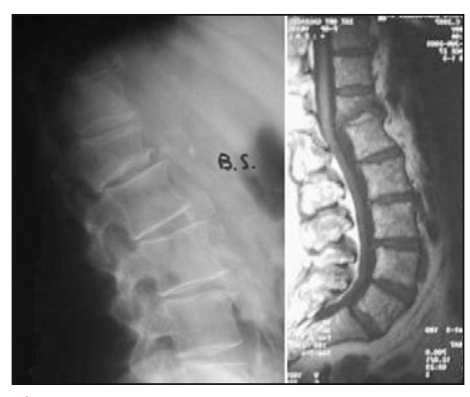

Fig. 1. Quadro radiologico pre-operatorio

\section{Caso clinico}

B.S., paziente di 70 anni, si è stata ricoverata per un dolore al passaggio dorso-lombare ingravescente e invalidante da oltre 2 mesi, insorto dopo un trauma a bassa energia. In anamnesi viene segnalata la presenza di diabete mellito non insulino-dipendente, ipertensione arteriosa, osteopo-

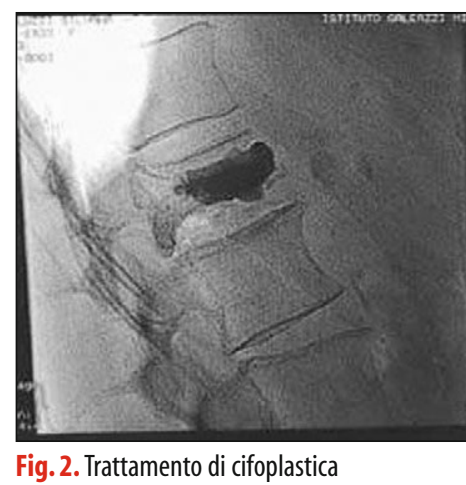

rosi (non in terapia), BPCO e aritmie cardiache. Le condizioni generali appaiono modeste.

Le immagini radiologiche ( $\mathrm{Rx}$ e RMN) mostrano una "wedge fracture" ("inferior") della XII D Tipo

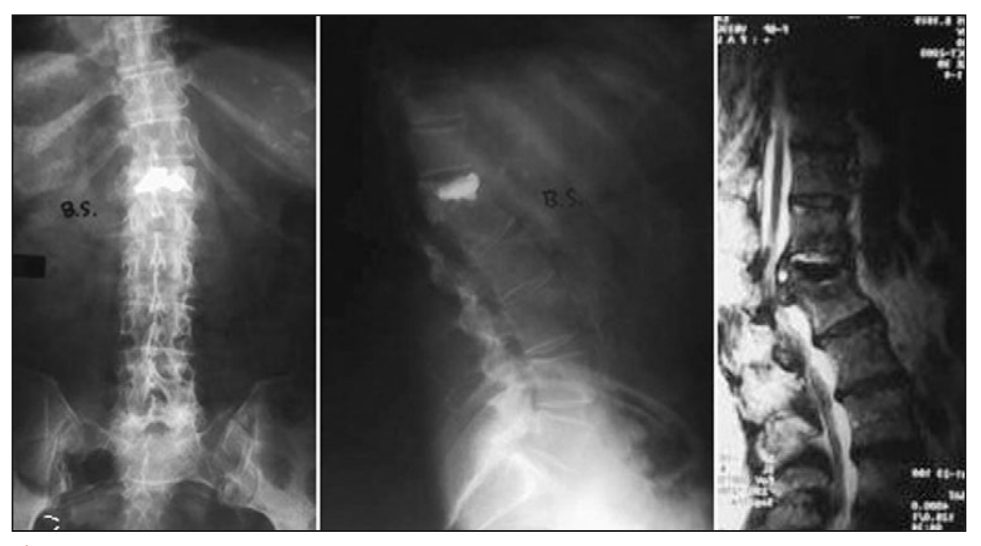

Fig. 3. Controllo a 3 mesi

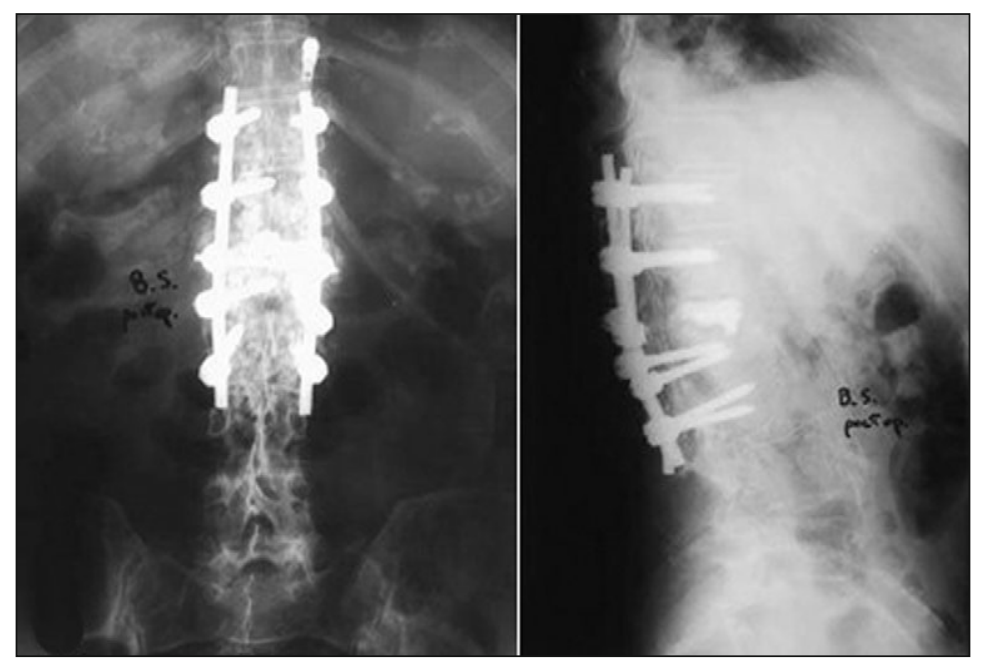

Fig. 4. Artrodesi vertebrale strumentata X D - II L

A1.2 secondo la classificazione delle fratture di Magerl (Fig. 1). Per la scarsa tolleranza ai corsetti e l'importante sintomatologia dolorosa, si decide di eseguire in anestesia generale un trattamento di cifoplastica (Fig. 2). Qualche ora dopo l'intervento la paziente presenta un arresto respiratorio che costringe al ricovero in terapia intensiva per 3 giorni. Al ritorno nel reparto di degenza, la paziente accusa un intenso dolore al passaggio dorso-lombare e iperpiressia, con un modesto rialzo degli indici di flogosi (VES-
PCR) Al controllo radiografico e RMN emerge un quadro di dubbia spondilodiscite.

Dalla letteratura [1-3] si evidenzia come siano ipotizzabili alme-

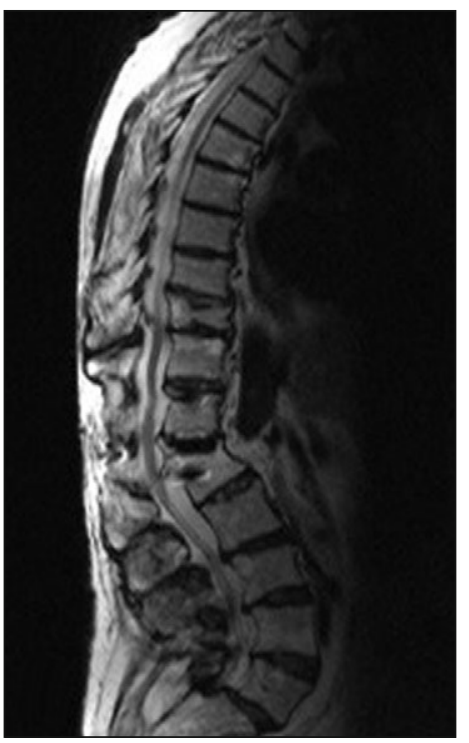

Fig- 5. Follow-up a 7 anni

\section{핀}

\section{Shoulder Instability Alternative Surgical Techniques}

Di Giacomo, G. C Costantini, A. De Vita, A. De Gasperis, N. (Eids) C) Springer 2011 Hardcover, 220 p. 100 illus. in cole ISBN 978-88-470-2034-4 Euro 145,55

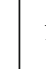

\section{Bibliografia}

1. Walker DH, Mummaneni P, Rodts GE Jr (2004) Infected vertebroplasty. Report of two cases and review of the literature. Neurosurg Focus 17:E6

2. Heo Dh, Chin DH, Yoon YS, Kuh SU (2009) Recollapse of previous vertebral compression fracture after percutaneous vertebroplasty. Osteoporos Int 20:473-480

3. Mueller M, Daniels-Wredenhagen M, Besch L et al (2009) Postoperative aseptic osteonecrosis in a case of kyphoplasty Eur Spine J 18[Suppl. 2]:213-216

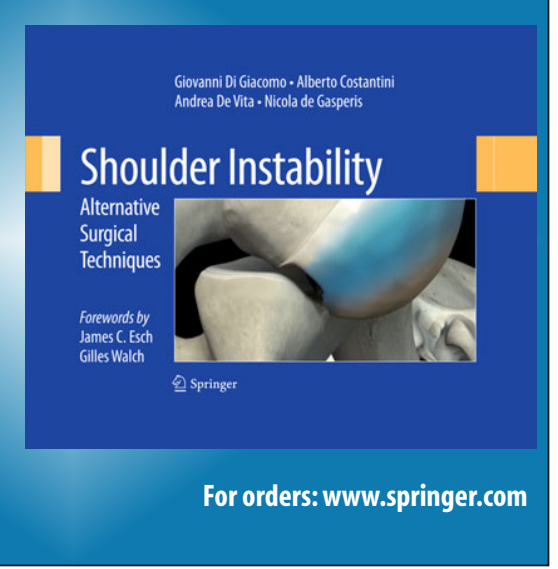

